\title{
A REASERCH ON COCOA POD HUSK ACTIVATED CARBON FOR TEXTILE INDUSTRIAL WASTEWATER COLOUR REMOVAL
}

\author{
Chethana Krishna $\mathbf{P}^{1}$ \\ ${ }^{I}$ Student, Department of Civil Engineering, Malnad College of Engineering Hassan, Karnataka, India
}

\begin{abstract}
One of the main problems in the environmental engineering all over the world is industrial wastewater treatment. Taking coloured wastewater into main consideration, the problem seems to be much worse. If coloured wastewater produced in industries is directly discharged to receiving bodies like streams, rivers, reservoirs etc. it interferes with the transmission of sunlight into the stream and lessens photo synthetic action. Property values decreases along the polluted river. The coloured wastewater interferes with oxygen absorption from the atmosphere. It is difficult to remove colour in water treatment plants. It is realized that the wastewater treatment can be done with eco friendly manner by using agriculture wastes. The efficient among the agricultural wastes is cocoa. Cocoa is a beverage crop which is a native of Amazon region of South America. In India Cocoa is mainly grown in Kerala, Karnataka, Andhra Pradesh and Tamil Nadu. Cocoa pod husk represents between 70 to $75 \%$ of the whole weight of the cocoa fruit, i.e. per each ton of cocoa fruit there will be between 700 to $750 \mathrm{Kg}$ of waste. During activation, it creates millions of pores at the surface of the carbon thus increasing the total surface area up to $1000 \mathrm{~m}^{2}$ per gram of carbon. The method introduced in the paper proves to be cost efficient and good performing. Results of the experiments show that cocoa pod husk is a material that can be used to produce activated carbon by chemical activation and $\mathrm{ZnCl} 2$ showed to be the best chemical activation agent based on the highest BET surface area $(780 \mathrm{~m} 2 / \mathrm{g}$ in the best case) and pore volume $(0.58 \mathrm{~m} 3 / \mathrm{g}$ in the best case).
\end{abstract}

The objective of the research is to investigate the efficiency of cocoa pod husk activated carbon for the colour removal from textile industrial wastewater. And also to compare the efficiencies of cocoa pod husk activated carbon and charcoal for colour removal purpose. This research gives an insight to a new approach towards environmental friendly wastewater treatment and sustainable development. The paper includes a research which is done by a case study in a textile industry: "Himatsingka Linens". The work focuses on sampling, testing wastewater characteristics (such as Biochemical Oxygen Demand, colour imparting compounds etc.), finding new methodologies for production of activated carbon from Cocoa pod husk, efficiency analysis of colour removal.

Keywords: Coloured industrial wastewater, Cocoa, Cocoa pod husk activated carbon, Colour removal, Efficiency optimization, Wastewater characteristics.

\section{INTRODUCTION}

Industrial wastewater treatment is one of the most important problems in front of any developing country. It is an important issue because if not given proper significance it creates a lot of public nuisances. India being a developing country was forced to concentrate on industrial development rather than sustainable development, eco friendly manufacturing processes in the earlier days; but it is the time for Indians to think environmental friendly developments that can sustain the planet earth livable place for the upcoming generations. The biggest problem in environmental engineering in the present scenario is wastewater management. The domestic wastewater being lower in strength, imparting lesser impact on receiving body requires lesser cost of treatment and lesser degree of treatment as compared to industrial wastewater. Industrial wastewater generally contains inorganic salts, acid and alkali, organic matter, suspended solids, floating solids, heated water, colour, toxic chemicals, micro organisms etc. It may contain radioactive materials and foam producing matters which make the treatment process much laborious. Colour is one of the industrial effluents which are difficult to remove among those mentioned.

\subsection{Physical Characteristics of Wastewater:}

For this research work physical characteristics of wastewater is very much significant. The principal physical characteristics of wastewater are its colour, odour, total solid content and temperature.

Colour is commonly considered as a qualitative characteristic that can be used to assess the general condition of wastewater. Colour change can be observed in wastewater with respect to time elapsed after its production. Wastewater that is light brown in colour is less than 6 hour old, while a light-tomedium grey colour is characteristic of wastewaters that have undergone some degree of decomposition or that have been in 
the collection system for some time. Lastly, if the colour is dark grey or black, it shows that the wastewater is typically septic, having undergone extensive bacterial decomposition under anaerobic conditions. The blackening of wastewater is often due to the formation of various sulphides, particularly, ferrous sulphide. This results when hydrogen sulphide produced under anaerobic conditions combines with divalent metal, such as iron, which may be present.

The determination of odour is becoming increasingly important in the field of wastewater management and treatment, as the general public has become more concerned with the proper operation of wastewater treatment facilities. The odour of fresh wastewater is usually not offensive, but the problem arises when a variety of odorous compounds are released when wastewater is decomposed biologically under anaerobic conditions. The principal odorous compound is Hydrogen Sulphide which smells like rotten eggs. Other compounds, such as Cadaverin Indol, Skatol and Mercaptan formed under anaerobic conditions or present in the effluents of pulp and paper mills (hydrogen sulphide, Mercaptan, Dimethyl sulphide etc.), can also cause a rather offensive odour. The effective method of measuring odour is by successive dilutions of the sample with odour-free water until the odour is no longer detectable.

The total solids in a wastewater consist of soluble compounds dissolved in water and insoluble or suspended solids the. The quantity of suspended solids content in the wastewater is found by drying and weighing the residue removed by the filtering of the sample. Generally when this residue is ignited the volatile solids are burned off. Volatile solids are presumed to be organic matter, although some organic matter will not burn and some inorganic salts break down at high temperatures. The organic matter consists mainly of fats, proteins and carbohydrates. Between $40 \%$ and $65 \%$ of the solids found in an average wastewater are suspended. Settleable solids, expressed as milliliters per liter, are those that can be removed by sedimentation. Ii is observed that usually about $60 \%$ of the suspended solids in a municipal wastewater are settleable. Solids present in the wastewater may be classified in another way as well: those that are volatilized at a high temperature $\left(600{ }^{\circ} \mathrm{C}\right)$ and those that are not. The former are known as volatile solids, the latter as fixed solids. Usually, volatile solids are organic.

The temperature of wastewater is generally higher than that of the water supply because of various industrial processes and warm municipal water being added. Most wastewater treatment schemes include biological processes that are temperature dependent. So the measurement of temperature is important.

\subsection{Effect of Coloured Industrial Wastewater on}

\section{Environment}

Coloured industrial wastewater treatment is a significant and concentration catching issue in the field of Waste management. Coloured wastewater is generally produced by dyes which are being used in industries such as textile, rubber, paper, plastic, cosmetic etc. Among these various industries, textile industry ranks first in usage of dyes. In textile industries dyes are use for adding colours to the fibers such as cotton; animal fibers such as wool and silk; and a wide range of synthetic materials such as nylon, polyester and acrylics. The raw materials used for manufacturing of any product in any industry, particularly dyes used in the textile industry determine the volume of water required for production as well as wastewater generated. The wastewater generated from the various processing units are desizing, scouring, bleaching, mercerizing, dyeing, printing, and packing require huge amount of organic chemicals of complex structure and all of them are not contained in the final product, became waste and caused disposal problems. The water used for above mentioned processes in textile industry is likely to be get coloured when it comes out in the form of industrial wastewater. The main parameters identified in the textile industry are $\mathrm{pH}$, Electrical conductivity (EC), Chloride, Sulphate, phenols, total dissolved solids (TDS), biochemical oxygen demand (BOD) and chemical oxygen demand (COD) and other solution substances. Colour is important among them because improper management of coloured wastewater leads to decrement of aesthetic value of receiving bodies like stream, river, lake etc. In turn it causes the reduction of site value along the bank of receiving bodies. Most of the times colour imparting effluents are toxic and also they cause visibility problem in the stream. The non-biodegradable characteristics of coloured industrial wastewater are also another problem which makes the environmental engineers to do research on colour removal methodologies. Further, the colour from textile industry is having more resistance to removal of the microorganisms present in the industrial wastewater treatment plants. It creates more problems for an engineer to treat and manage wastewater from textile industries. The interference caused by coloured wastewater with absorption of oxygen from atmosphere makes the dissolved oxygen content of water to get reduced by huge extent. It causes threat to aquatic life. Pollution caused by their dead floating bodies again increases the biochemical oxygen demand. Decrement in the photosynthetic action due to interference to light entrance is also another serious problem. Hence many investigators have examined a wide variety of absorbents like fly-ash, peat, sawdust, brown coal, bagasse activated carbon to remove colour from textile industry wastewater rather than removal of other pollutants in the textile industry wastewater. 


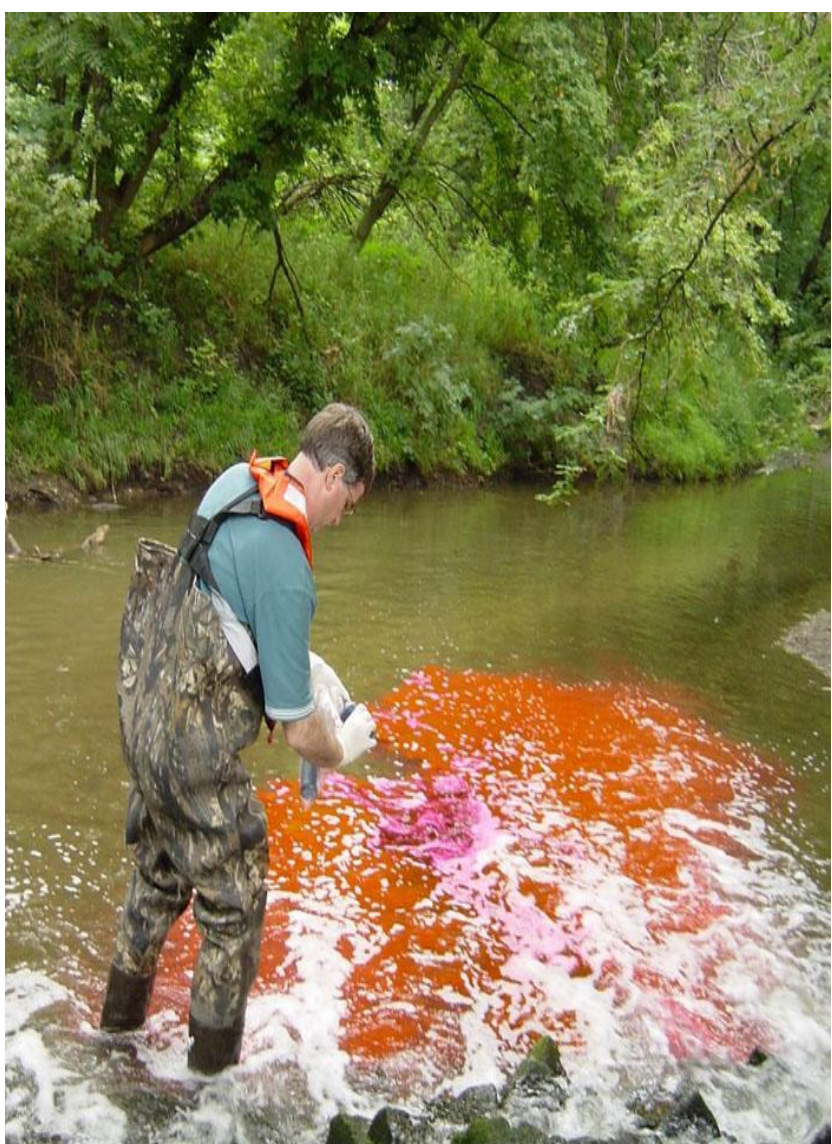

Fig 1: Coloured wastewater discharge to streams

\section{ACTIVATED CARBON FOR INDUSTRIAL} WASTEWATER TREATMENT

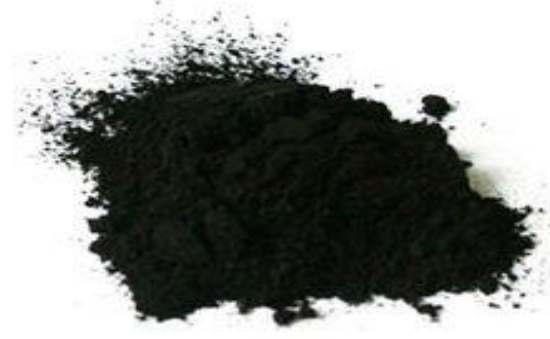

Fig 2: Powdered activated carbon

Activated carbon is a material mostly derived from charcoal. It is the most widely used adsorbent due to its excellent adsorption capability in removing various pollutants in the water and wastewater. The structure of activated carbon has a very large surface area $-1 \mathrm{lb}$ of granular activated carbon has the surface area of 125 acres. The activated carbon surface is non-polar which results in an affinity for non-polar adsorbents such as organics. Activated carbon is very effective in air and water purification applications, as well as precious metal recovery or removal.

\subsection{Adsorption Parameters of Activated Carbon}

\subsubsection{Pore Size}

Correct pore size distribution is necessary to facilitate the adsorption process by providing adsorption sites and the appropriate channels to transport the adsorbate. Activated Carbon Pores can be divided into three general sizes: Micro-pores (diameter in the range of less than $2 \mathrm{~nm}$ ) Meso-pores (diameter in the range of $2-25 \mathrm{~nm}$ ) Macro-pores (diameter in the range of above $25 \mathrm{~nm}$ )

\subsubsection{Iodine Number}

The Iodine number is the most fundamental parameter used to characterize activated carbon performance, measure activity level (higher number indicates higher degree of activation) and measure the micro pore $(0-20 \AA)$ content. This number is equivalent to the surface area of activated carbon in $\mathrm{sq} \mathrm{m} / \mathrm{g}$ between 900 - 1100. The iodine number is also the standard measure for liquid phase applications.

\subsubsection{Hardness / Abrasion Number}

It is the measure of activated carbon's resistance to attrition. This is an important indicator of activated carbon to maintain its physical integrity and withstand frictional forces imposed by backwashing etc.

\subsubsection{Ash Content}

It reduces overall activity of activated carbon. Hence efficiency of reactivation of activated carbon reduces. Metals can leach out of activated carbon resulting in discoloration. Acid/water soluble ash content is more significant than total ash content.

\subsubsection{Apparent Density}

Higher density provides greater volume activity and normally indicates better quality activated carbon.

\subsection{Properties of Activated Carbon}

Although activated carbon is found to be good adsorbent to treat industrial wastewater, its use is often limited due to high cost. However, many researchers developed methodologies to produce activated carbon from biomaterials and agricultural wastes. The costs of the activated carbon prepared from biomaterials are negligible when compared to the cost of commercial activated carbon

Some of the activated carbons used to treat the industrial wastewater in the recent past are corncob, wheat straw 
groundnut husk, rice husk, barley husks tea leaves carbon, saw dust modified rice hull, eucalyptus bark, agricultural wastes, and sugar cane bagasse ash and spent activated carbon.

This research paper also concentrates about production of activated carbon, but using cocoa pod husk. Research activities are going on in the same area. But many researchers are using activated carbon for treatments like De fluoridation, Toxin removal etc. The paper consists of the report on production activated carbon by Cocoa pod husk and optimization of its efficiency.

The table shown below tabulates the properties of activated carbon produced by coconut, coal, lignite and wood.

Table 1: Properties of activated carbon produced by various materials

\begin{tabular}{|l|l|l|l|l|}
\hline & \multicolumn{3}{|l|}{ Material used for activated carbon production } \\
\hline Property & Coconut & Coal & Lignite & Wood \\
\hline $\begin{array}{l}\text { Micro-pores } \\
\text { (diameter } \\
\text { range less } \\
\text { than 2nm) }\end{array}$ & High & High & Medium & Low \\
\hline $\begin{array}{l}\text { Macro- } \\
\text { pores } \\
\text { (diameter } \\
\text { range above } \\
25 \text { nm) }\end{array}$ & Low & Medium & High & High \\
\hline Hardness & High & High & Low & n/a \\
\hline Ash & $5 \%$ & $10 \%$ & $20 \%$ & $5 \%$ \\
\hline $\begin{array}{l}\text { Water } \\
\text { Soluble Ash }\end{array}$ & High & Low & High & Medium \\
\hline $\begin{array}{l}\text { Dust } \\
\text { Reactivation }\end{array}$ & Good & Good & Poor & None \\
\hline $\begin{array}{l}\text { Apparent } \\
\text { Density }\end{array}$ & $0.48 \mathrm{~g} / \mathrm{cc}$ & $\begin{array}{l}0.48 \\
\mathrm{~g} / \mathrm{cc}\end{array}$ & $0.4 \mathrm{~g} / \mathrm{cc}$ & $0.35 \mathrm{~g} / \mathrm{cc}$ \\
\hline Iodine No. & 1100 & 1000 & 600 & 1000 \\
\hline
\end{tabular}

\subsection{Cocoa (Theobroma Cacao)}

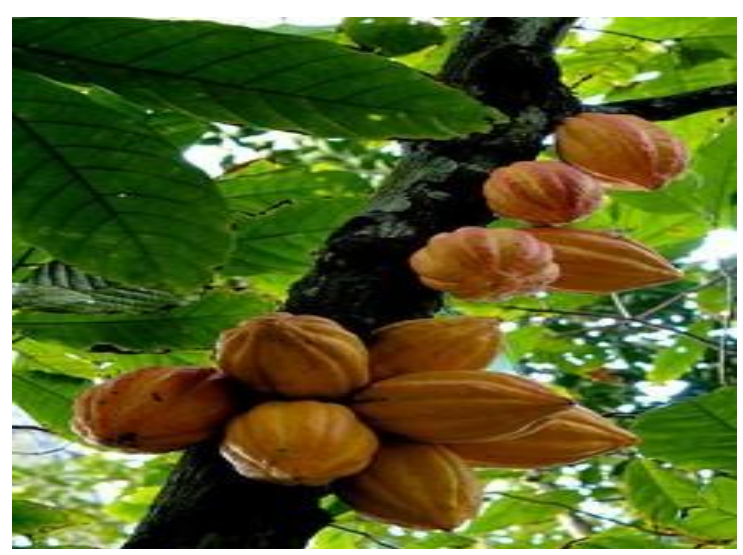

Fig 2: Cocoa fruit
For the research work Cocoa pod husk was available from coastal areas like Mangalore, Kasaragod and some northern Malabar part of Kerala. In these areas Cocoa is a main commercial crop. Disposal of agricultural wastes like Cocoa pod husk is a problem for the farmers. Cocoa pod husks thrown without scientific methodology of management is a source for mosquito growth. The thought of usage of one waste for the management of another waste is the inspiration for this work. The efficient usage of this agricultural waste for wastewater management proves the Chinese proverb which says "Waste is not waste; it is the resource put in the wrong place".

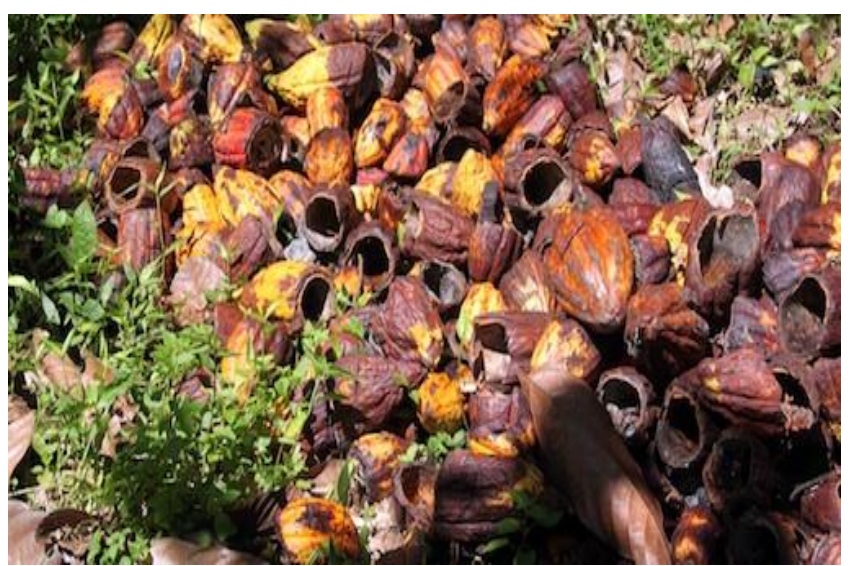

Fig 4: Cocoa pod disposal problem

\section{COLLECTION AND ANALYSIS OF TEXTILE INDUSTRY WASTEWATER}

For the research work untreated coloured wastewater is collected from "Himatsingka Linens", Hanumanthapura, Hassan, Karnataka with the help of airtight sterilized bottles. Then, took the wastewater samples to the Environmental Laboratory of Malnad College of Engineering and then they were stored in refrigerator at a temperature of $278 \mathrm{~K}$ for analyzing colour intensity in later stage. It is needed to reduce the colour in the textile industry wastewater. So bioadsorbents like orange peels, neem leaves, peanut hulls and coconut coir pith powders are selected and conducted the batch adsorption study with different process parameters like adsorbent dosage, temperature, contact time and agitator speed. Further, experiments are conducted with and without aeration, and analyzed the colour intensity in the textile industry wastewater as per the standard procedure stipulated by APPA, AWWA and WEF, 2005.

\subsection{Material and Methods}

\subsubsection{Raw Material}

Cocoa pod husk samples were collected from four different areas in Kasaragod, Kerala. Based on observations in laboratory the characteristics of cocoa pod husk are: moisture 
content $10.04 \pm 0.02 \%$, ash content $12.6 \pm 0.19 \%$, crude fiber content $33.40 \pm 0.15 \%$, hemi-cellulose content $35.26 \pm 0.055 \%$, lignin content $0.95 \pm 0.04 \%$, and cellulose content $41.9 \pm 0.09$ $\%$. In addition, the following compounds in cocoa pod husk have also been observed: crude protein $6.2 \%$, ether extract 1.4 $\%$, calcium $1.63 \mathrm{~g} / \mathrm{kg}$, phosphorus $0.17 \mathrm{~g} / \mathrm{kg}$, potassium 2.18 $\mathrm{g} / \mathrm{kg}$, sodium $0.36 \mathrm{~g} / \mathrm{kg}$, magnesium $0.24 \mathrm{~g} / \mathrm{kg}$, copper 135.2 $\mathrm{mg} / \mathrm{kg}$, manganese $45.6 \mathrm{mg} / \mathrm{kg}$, and zinc $90.3 \mathrm{mg} / \mathrm{kg}$.

\subsubsection{Reagents}

The Reagents used for production of activated carbon are listed:

All the chemicals were of analytical reagent grade and need not to be further purified. The activation chemicals $\mathrm{ZnCl}$, $\mathrm{K} 2 \mathrm{CO} 3$ were used and both can be purchased from market for justifiable amount, and $\mathrm{KOH}$ is also used. Sodium arsenate dibasic heptahydrate (HAsNa2O4.7H2O) was used for preparing the $100 \mathrm{mg} / \mathrm{l}$ as stock solution. It is used for for adsorption experiments. The stock solution was preserved with ultrapure concentrated $(65 \%)$ nitric acid (HNO3) in order to have a final acid concentration of $0.2 \%$ in the solution. De-ionized water from a Millipore Milli-Q water system was used for all dilutions of the stock solution.

\subsubsection{Carbonization Equipment}

The equipment for the activation of cocoa pod husk is seen in Figure 1. The equipment contained a nitrogen supply, a nitrogen mass flow controller, a furnace, a tubular reactor, a ceramic container for the sample and a trap for gaseous compounds.

\subsubsection{Production of Activated Carbon}

Cocoa pod husk was dried at $80^{\circ} \mathrm{C}$ until a constant weight was obtained, ground and sieved to two fractions: $0.25-0.5 \mathrm{~mm}$ and $0.5-1 \mathrm{~mm}$. $\mathrm{K} 2 \mathrm{CO} 3, \mathrm{KOH}$ and $\mathrm{ZnCl} 2$ were used as activation chemicals for raw material in a weight proportion 1/1. In the case of $\mathrm{K} 2 \mathrm{CO} 3$ and $\mathrm{KOH}$ water was added to the samples in a weight proportion $1 / 1$ (water/mix), dried at $100^{\circ} \mathrm{C}$ overnight and carbonized at different temperatures 500 , 650 and $800^{\circ} \mathrm{C}$. In the case of $\mathrm{ZnCl} 2$ samples were carbonized directly without water addition and dried. The heating rate of $10^{\circ} \mathrm{C} / \mathrm{min}$ was applied to reach the carbonization temperature, in which the samples were kept for two hours and then cooled down to room temperature. The whole process of carbonization was done under nitrogen atmosphere (150 $\mathrm{ml} / \mathrm{min})$.

After carbonization, the samples activated with $\mathrm{K} 2 \mathrm{CO} 3$ were washed with boiled distilled water and room temperature water. The samples activated with $\mathrm{KOH}$ and $\mathrm{ZnCl} 2$ were washed with a dilute solution of $\mathrm{HCl}(0.5 \mathrm{~N})$ and room temperature water. Finally, all samples were dried at $100^{\circ} \mathrm{C}$ overnight, ground and sieved on a mesh of $0.25 \mathrm{~mm}$ pore size.
Table 1 presents the conditions during the activations and the names used for the activated carbons produced.

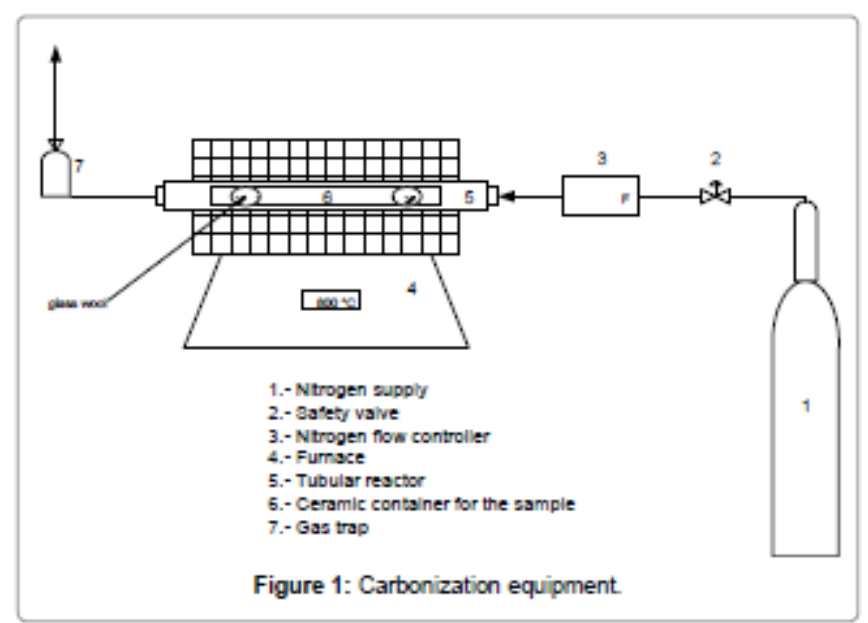

\begin{tabular}{|c|c|c|c|c|c|c|}
\hline \multirow{4}{*}{$\begin{array}{l}\text { Carbonization } \\
\text { Temperature } \\
\left({ }^{\circ} \mathrm{C}\right)\end{array}$} & \multicolumn{6}{|c|}{ Chemical Activator } \\
\hline & \multicolumn{2}{|l|}{$\mathrm{K}_{2} \mathrm{CO}_{3}$} & \multicolumn{3}{|l|}{$\mathrm{KOH}$} & $\mathrm{ZnCl}_{2}$ \\
\hline & \multicolumn{2}{|c|}{ Particle size (mm) } & \multicolumn{2}{|c|}{ Particle size (mm) } & \multicolumn{2}{|c|}{$\begin{array}{l}\text { Particle size } \\
(\mathrm{mm})\end{array}$} \\
\hline & $0.25-0.5$ & $0.5-1$ & $0.25-0.5$ & $0.5-1$ & $0.25-0.5$ & $0.5-1$ \\
\hline 500 & $\mathrm{CPH}-18$ & $\mathrm{CPH}-15$ & $\mathrm{CPH}-10$ & $\mathrm{CPH}-12$ & $\mathrm{CPH}-24$ & CPH-21 \\
\hline 650 & $\mathrm{CPH}-16$ & $\mathrm{CPH}-17$ & $\mathrm{CPH}-08$ & $\mathrm{CPH}-11$ & $\mathrm{CPH}-22$ & $\mathrm{CPH}-23$ \\
\hline 800 & $\mathrm{CPH}-13$ & $\mathrm{CPH}-14$ & $\mathrm{CPH}-07$ & CPH-09 & $\mathrm{CPH}-2 \mathrm{O}$ & CPH-19 \\
\hline
\end{tabular}

Table 1: Description of conditions during the activation process.

Fig 5: Carbonization equipment

\section{RESULTS AND DISCUSSIONS}

\subsection{Characterization of Activated Carbon}

Activated carbons obtained were characterized using BET surface area $(\mathrm{m} 2 / \mathrm{g})$, Langmuir surface area $(\mathrm{m} 2 / \mathrm{g})$, pore volume $(\mathrm{m} 3 / \mathrm{g})$, average pore size $(\mathrm{nm})$, moisture content $(\%)$, dry matter content $(\%)$, ash content $(\%)$, yield (\%) and bulk density (kg/l) measurements. Micro meritics ASAP 2020 Surface area and porosity analyzer was used to determine BET surface area, Langmuir surface area, pore volume and average pore size. The BET method was used to calculate the surface area, based on selected $\mathrm{N} 2$ adsorption data within the $\mathrm{p} / \mathrm{p} 0$ range of $0.057-0.203$. The total pore volume and the average pore were derived using the BJH (Barret-Joyner-Halenda) method. Moisture was determined by a gravimetric method and ash content of the carbons was determined using the standard ASTM procedure D2866-94. The yield was calculated by the following equation

$$
\text { Yield }(\%)=\mathrm{FW} \times 100 \%
$$

Where FW is the final weight after carbonization process and IW is the initial raw material weight used before the addition of a chemical activation agent. 
The best five samples according to the chemical activation agent, surface area and ash content were selected to carry out deeper analysis such as carbon content (\%), impurities content $(\mathrm{mg} / \mathrm{kg})$ and existence of impurities and surface uniformity (Fe-SEM images). Impurities were analyzed by Inductively Coupled Plasma Optical Emission Spectroscopy (ICP-OES) Perkin Elmer Optical Emission Spectrometer Optima 5300 DV. The samples were first dissolved with a mixture of $\mathrm{HNO} 3, \mathrm{H} 2 \mathrm{O} 2, \mathrm{HF}$ and $\mathrm{HCl}$ in microwave oven before analysis with ICPOES. Fe-SEM images were obtained using a Field Emission Scanning Electron Microscopy ZEISS ULTRA plus equipped with Oxford Instruments INCA-X-act EDS detector.

\subsection{Adsorption Experiments}

Batch adsorption experiments were carried out to test the arsenic adsorption capability of the five best activated carbons obtained. The experiments were conducted at room temperature. The initial arsenic concentration of $100 \mathrm{mg} / \mathrm{l}$ in the $200 \mathrm{ml}$ batches was achieved by diluting the as stock solution with Milli-Q water. The initial $\mathrm{pH}$ of the arsenic solution was between 6 and 7 and the experiments were conducted without adjusting the solution $\mathrm{pH}$ during the test. The activated carbon loadings were $0.5 \mathrm{~g} / \mathrm{l}$ and $1.0 \mathrm{~g} / \mathrm{l}$. The solutions were shaken with a mechanical shaker Certomat at $175 \mathrm{rpm}$ for six hours. Samples were taken periodically at the initial time, 5, 15, 30, 60, 120, 180, and 240 minutes, filtered through $0.45 \mu \mathrm{m}$ syringe filters and acidified with p.a. nitric acid in order to maintain the preservability of the samples. Arsenic concentration of the samples was analyzed using Graphite Furnace Atomic Absorption Spectrometry (GF-AAS) Perkin Elmer A Analyst 600.

\subsection{Graphical Representation}

Work is carried out by simple methodology. I.e. first the validation of idea is verified by using arbitrary amount of activated carbon produced by Cocoa pod husk. Then the trials are conducted by altering the amount of activated carbon used for particular quantity of wastewater. The state is reached where the usage of activated carbon for treatment of wastewater is less so that the efficiency is higher. For that mass of activated carbon, where there is no wastage of material produced and no requirement of longer time duration for colour removal, the readings are tabulated and graph is plotted.

The graph shows the adsorption process of colour by acivated carbon with respect to time. It is clear that in every case there is a higher tendency of adsorption at the beginning of the experiment and after certain time the tendebcy reduces gradually. It indicates that the pores are being fillled by colouring materials and efficincy decreases. But it is noteworthy point that it removes considerable quantity of colour from wastewater.

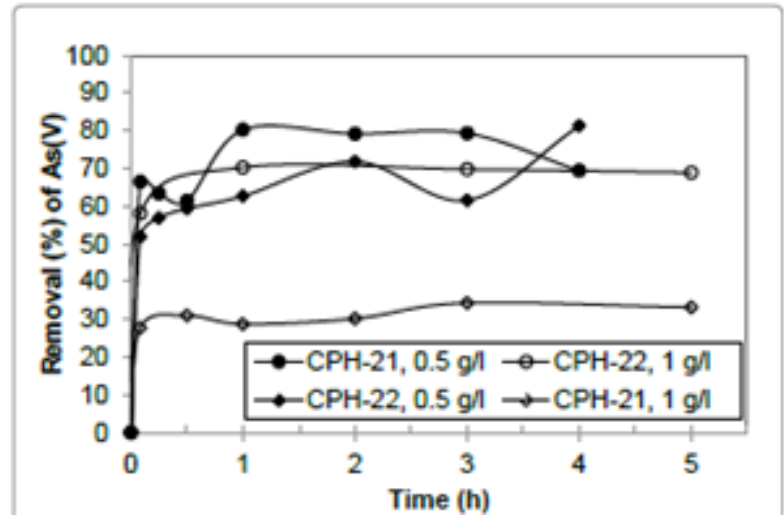

Fig 6: Graph showing removal of ash v/s time.

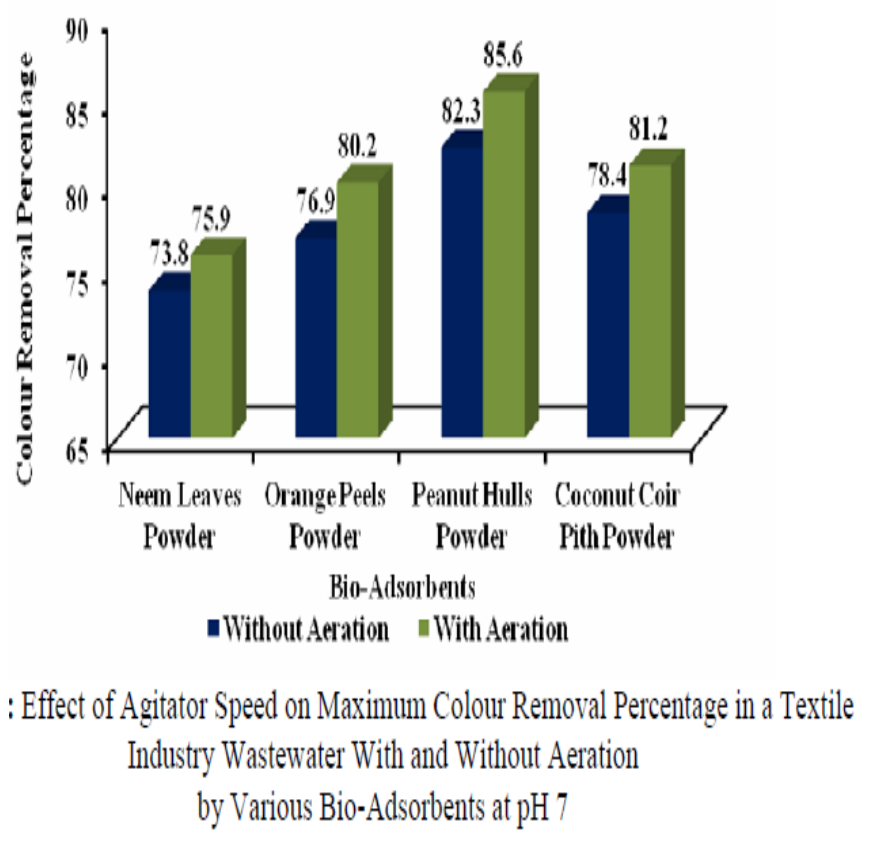

Fig 7: Effect of aeration on colour removal. 


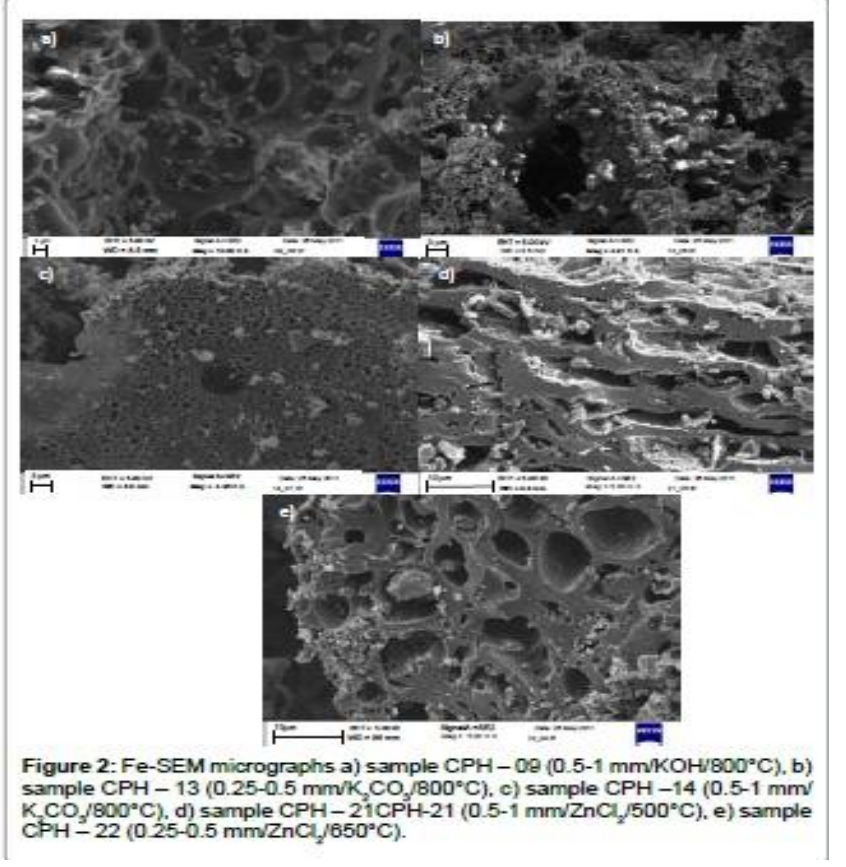

Fig 8: Pores in activated carbon

\section{CONCLUSIONS}

This research studied the utilization of waste biomass, i.e. cocoa pod husk, as a precursor for activated carbon production. The raw material was chemically activated with activation agents like $\mathrm{ZnCl} 2$ and characterized for the physicochemical properties. Five best samples were further studied for the adsorption of arsenic. It was observed that cocoa pod husk is a material that can be used to prepare activated carbon by chemical activation. It gives adsorption materials with high surface areas. From the experiment $\mathrm{ZnCl} 2$ showed to be the best chemical activation agent in the preparation of activated carbon from cocoa pod husk according to the highest BET surface area $(780 \mathrm{~m} 2 / \mathrm{g}$ in the best case) and pore volume $(0.58$ $\mathrm{m} 3 / \mathrm{g}$ in the best case), lowest ash content $(6.14 \%$ in the best case), and highest carbon content (86.1\% in the best case), compared with other chemicals. Activated carbon produced by using $\mathrm{ZnCl} 2$ is proved to be better, as they show above mentioned characteristics which are ideal for wastewater colour removal. Activated carbons activated by $\mathrm{ZnCl} 2$ are capable to adsorb As(V), up to removal levels of $80 \%$ in less than one hour at the experimental conditions applied (initial $\mathrm{pH}$ 6-7, activated carbon concentration $0.5 \mathrm{~g} / 1$ and $1.0 \mathrm{~g} / \mathrm{l}$, initial As concentration $100 \mathrm{ppb}$ ).

\section{REFERENCES}

[1]. Aharoni C and Ungarish, M (1977), "Kinetics of activated chemisorptions Part 2 Theoretical models", Journal of the Chemical Society, Faraday Transactions, 73, pp 456-464

[2]. Ademiluyi, F. T., Amadi, S. A., Amakama, A. A. \& Nimisingha, J. 2009. Adsorption and Treatment of Organic
Contaminants using Activated Carbon Waste Nigerian Bamboo J. Appl. Sci Environ Manage 13, 39 - 47

[3]. APPA, AWWA, and WEF (2005), "Standard methods for the examination of water and wastewater", 21th edition, APHA Publication, Washington D.C., 2005.

[4]. Aravind, K.S. and Prem, N.T (2003), "Removal of basic dye from industrial wastewater", Indian Journal of Chemical Technology, 10, pp 211-216.

[5]. Hoda, R.G (2010), "Treatment and reuse of wastewater in the textile industry by means of coagulation and adsorption techniques", Journal of Applied Sciences Research, 6(8), pp 964-972.

[6]. Irina, I.S., and Romen, B (2008), "Wastewater characteristics in textile finishing mills", Environmental Engineering and Management Journal, 7(6), pp 859 